\title{
Development of an Automated Delivery Vehicle
}

\author{
D.L.C.K. Liyanage ${ }^{1}$, H.G.T. Pathum ${ }^{2}$, A.D.S. Madusanka ${ }^{3}$, R.L.W. Koggalage ${ }^{4}$ \\ 1,2,3,4 University of Vocational Technology, Sri Lanka
}

\begin{abstract}
The Covid - 19 pandemic has gone out of control all over the world causing nearly five million deaths. Number of affected persons keeps increasing and there is a huge problem of providing essential items for them. The objective of this project is to design an Automated Delivery System, which is suitable for Sri Lanka during such pandemic situations. Because of the situations like this, delivery people do not like to reach affected areas even for business. Therefore, the people living in such areas face the problem of getting even the basic needs such as essential food items and medicine. As a solution, an unmanned automated delivery vehicle system has been proposed in this research, which can be mainly used in locked down areas in Sri Lanka. It can be used to deliver goods without a driver to the required places, while maintaining the health guidelines and required security and safety. This can be further extended to certain areas such as private apartments, hospitals, supermarkets etc. to deliver items in automated way.
\end{abstract}

KEYWORDS: ADV- Automated Delivery Vehicle, AGV- Automated Guided Vehicle, ESC- Electronic Speed Controller

\section{INTRODUCTION}

In the past people, use many different ways to deliver goods from one place to another. After the wheel was invented, they made a cart and then used it for delivery. After the revolutionary invention of steam engine, they used the train for delivery. When considering the history of world, so many delivery systems appeared. Many of them can be considered as developments of old delivery systems. Time to time they have been upgraded with new technology. However, still most of the systems depend on human interaction. The concept of automated delivery vehicle (ADV) can be considered as a kind of revolutionary upgrade for existing goods delivery systems. The main essential feature for automated system is to control it without direct human interaction. Few such systems are used by world branded companies for delivering their goods for customers[1]. However, the proposed system differs from other systems use in the world, as this is a low cost system suitable for poor and developing countries. This system is specially designed to solve major problems encountered with Covid - 19 pandemic. As Sri Lanka also has to face this Covid - 19 pandemic situation, the government of Sri Lanka introduced new rules and regulations to face this. Main requirement to control the spreading of it is to isolate affected areas so that people cannot travel in or out. In such situations, it is important to deliver essential items for needy people and the proposed automated delivery vehicle is an ideal solution for this

\section{LITERATURE REVIEW}

From the influence of the Automated Delivery Vehicle in
1980, the Autonomous car was invented. Then with that project, Automated Delivery Vehicles were invented for various purposes [2].

The first significant development for the AGV industry was introducing a unit load vehicle in the mid-1970s. This unit load AGVs gained widespread acceptance in the material handling marketplace because of their ability to serve several functions; a work platform, a transportation device, and a link in the control and information system for the factory[3].

Dylan Dennis et. al.[4] have researched the potential impact on fright efficiency and travel of road Autonomous Delivery Robots. In there, they explain that - Road Autonomous Delivery Robots (RADRs) may soon deliver groceries and parcels to commercial and residential customers [4].

Mohsin Raza has researched levels, technologies, impacts, and concerns at Autonomous Vehicles[5].

U.S Department of Transportation has said Automated Urban freight Delivery is attracting interest from industry. Here they have explained a variety of different Automated Delivery Vehicle concepts ranging from small delivery to light and medium-duty vehicles[6].

In his paper [7], Justinas Liuima said Covid - 19 increases demand for Autonomous Vehicles. He explained that Covid - 19 pandemics had had a significant impact on the mobility sector.

According to above literature, following are the advantages and disadvantages of ADV.

\section{Advantages}

- Decreased the number of accidents.

- Lessens traffic jams.

- Cost-saving. 
- $\quad$ Time saving.

\section{Disadvantages}

- Loss of jobs.

- New security concerns.

- Expensive.

- Safety and security concerns.

- Prone to hacking.

- When considering those systems, they are not suitable for developing countries such as Sri Lanka mainly due to cost considerations, the network problems and poor GPS systems. So as a solution this system has been developed specially for Sri Lanka, with following features. This system powered up with RF Technology.

- This system only working for $1 \mathrm{Km}$ range.

- For control this don't need any special knowledge.

- Mainly this is designed to provide a support system during a disaster situation where it is unsafe for human approach. (Eg :- Locked Down Streets)

\section{METODOLOGY}

\section{Design}

The basic design for the automated delivery vehicle consists of three major systems. They are,
1. Camera system
2. Door control system
3. Vehicle moving system

\subsection{Camera system}

Here another main thing is the camera system. More camera systems were tested and but those systems cannot be, apply in Sri Lanka. So the cause of that here use the FPV camera system for this device. This system also controls RF signals and, from this, can quickly get video footage immediately. This is an essential system for this vehicle, which means that the video provides by this system decides the road that ADV should go. Cause of this reason, this system is essential for this vehicle.

\subsection{Door Controlling System}

This system is a more important system of this automated delivery vehicle. This means here all the good under the chamber of this, and that chamber consists of goods. To protect them and ease off the work, we developed an automated door controlling system for it. This consists of an $\mathrm{RS}-550$ motor that connects to the thread bar. This door is controlled by an Arduino microcontroller, controlled by the switches on ADV and transmitter.

\subsection{Vehicle Moving System}

This is the most important part of ADV. Because of this system, control the vehicle and their movements. This system consists of two wiper motors to handle the vehicle and them controlled by ESC, and that ESC is controlled from the handler's transmitter. This system we divide into the mechanical system and electronic system.

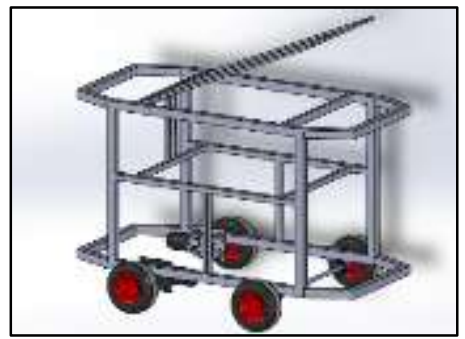

Figure 1 - Solid Works Design

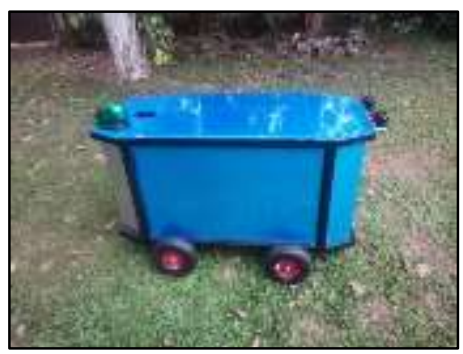

Figure 2 - Automated Delivery Vehicle

\section{CALCULATIONS}

For selecting a suitable motor for $\mathrm{ADV}$ it is required to do some calculations and the summary of results can be found as shown in Table 1.

Table 1: summary of calculated values

\begin{tabular}{|l|l|}
\hline Acceleration (a) & $2 \mathrm{~ms}^{-2}$ \\
\hline Gravitation (g) & $9.8 \mathrm{Kgms}^{-}$ \\
\hline $\begin{array}{l}\text { Rolling friction between tire and } \\
\text { the road (c) }\end{array}$ & 0.04 \\
\hline $\begin{array}{l}\text { Effective radius if the ADV } \\
\text { wheel (R } \mathrm{R}_{\text {eff.whee/ }}\end{array}$ & $0.25 \mathrm{~m}$ \\
\hline Maximum speed of ADV (V) & $1.19 \mathrm{~ms}^{-1}$ \\
\hline
\end{tabular}

Parameters and symbols used in calculations are shown in table 2

Table 2: Symbols used for calculations

\begin{tabular}{|l|l|}
\hline Description of parameter & Symbol \\
\hline Total Force Requirement by ADV & $\mathrm{F}_{\text {ADV }}$ \\
\hline Force to drive the ADV & $\mathrm{F}_{\text {Moving }}$ \\
\hline Friction that must be resisted & $\mathrm{F}_{\text {Friction }}$ \\
\hline Total mass of ADV and Contains & $\mathrm{m}$ \\
\hline Maximum acceleration & $\mathrm{a}$ \\
\hline Rolling friction between tire and the road & $\mathrm{c}$ \\
\hline Total normal force & $\mathrm{N}$ \\
\hline Mass of the ADV & $\mathrm{M}_{\mathrm{ADV}}$ \\
\hline Mass of the contains & $\mathrm{M}_{\mathrm{ADV}}$ \\
\hline Gravitation & $\mathrm{g}$ \\
\hline Motor torque requirement & $\mathrm{T}$ \\
\hline Effective radius of the ADV wheel & $\mathrm{R}_{\text {eff.whee/ }}$ \\
\hline Motor Power Requirement & $\mathrm{P}$ \\
\hline Maximum speed of ADV & $\mathrm{V}$ \\
\hline
\end{tabular}




$$
\begin{aligned}
\mathrm{F}_{\text {Moving }} & =\mathrm{m} \times \mathrm{a} \\
& =42{\mathrm{Kg} \mathrm{x} 2 \mathrm{~ms}^{-2}} \\
& =84 \mathrm{Kgms}^{-2} \\
& =84 \mathrm{~N} \\
\mathrm{~N} \quad & =\left(\mathrm{m}_{\mathrm{ADV}}+\mathrm{m}_{\text {Contains }}\right) \cdot \mathrm{g} \\
& =(32 \mathrm{Kg}+10 \mathrm{Kg}) \times 9.8 \mathrm{~ms}^{-2} \\
& =411.6 \mathrm{~N}
\end{aligned}
$$

Then the frictional force can be obtained as:

$$
\begin{aligned}
\mathrm{F}_{\text {Friction }} & =\mathrm{c} . \mathrm{N} \\
& =0.04 \times 411.6 \mathrm{~N} \\
& =16.464 \mathrm{~N} \\
\mathrm{~F}_{\mathrm{ADV}}= & \mathrm{F}_{\text {Moving }}+\mathrm{F}_{\text {Friction }} \\
= & 84 \mathrm{~N}+16.464 \mathrm{~N} \\
= & 100.464 \mathrm{~N} \\
\mathrm{~T}= & \mathrm{F}_{\mathrm{ADV}} \times \mathrm{r}_{\text {eff. wheel }} \\
= & 100.464 \mathrm{~N} \times 0.25 \mathrm{~m} \\
= & 25.116 \mathrm{Nm} \\
\mathrm{P} & \mathrm{F}_{\mathrm{ADV}} \times \mathrm{V} \\
= & 100.464 \mathrm{~N} \times 1.19 \mathrm{~ms}^{-1} \\
= & \underline{119.55 \mathrm{~W}}
\end{aligned}
$$

Motor Power Calculation (without load Contains)

$$
\begin{aligned}
& \mathrm{F}_{\text {moving }}=\mathrm{m} \mathrm{x} \mathrm{a} \\
& =32 \mathrm{Kg} \times 2 \mathrm{~ms}^{-2} \\
& =64 \mathrm{Kgms}^{-2} \\
& =64 \mathrm{~N} \\
& \mathrm{~N}=\left(\mathrm{M}_{\mathrm{ADV}}\right) \times \mathrm{g} \\
& =32 \mathrm{Kg} \times 9.8 \mathrm{~ms}^{-2} \\
& =313.6 \mathrm{~N} \\
& \begin{aligned}
\mathrm{F}_{\text {Friction }} & =\mathrm{C} . \mathrm{N} \\
& =0.04 \times 313.6 \mathrm{~N} \\
& =12.54 \mathrm{~N}
\end{aligned} \\
& \mathrm{~F}_{\mathrm{ADV}}=\mathrm{F}_{\text {Moving }}+\mathrm{F}_{\text {Friction }} \\
& =64 \mathrm{~N}+12.54 \mathrm{~N} \\
& =76.54 \mathrm{~N} \\
& \mathrm{~T}=\mathrm{F}_{\mathrm{ADV}} \mathrm{x} \text { Reff. wheel } \\
& =76.54 \mathrm{~N} \text { x } 0.25 \mathrm{~m} \\
& =19.14 \mathrm{Nm} \\
& \mathrm{P}=\mathrm{F}_{\mathrm{ADV}} \mathrm{x} \mathrm{V} \\
& =76.54 \mathrm{~N} \text { x } 1.19 \mathrm{~ms}^{-1} \\
& =\underline{\underline{91.08 \mathrm{~W}}}
\end{aligned}
$$

Here, the calculated motor power requirement is $119.55 \mathrm{~W}$ required with contains $91.08 \mathrm{~W}$ required without contains. But we use four wiper motors from 150W. Cause of that we can achieve this power quickly that wiper Motor.

$$
\begin{array}{r}
\text { Power from Wiper Motors }=150 \mathrm{~W} \times 2 \\
=300 \mathrm{~W}
\end{array}
$$

So, whether with or without contains ADV can run from these motors.

The charging time of the battery was calculated.

$$
\begin{aligned}
\text { Battery Charging Time } & =\frac{\text { Battery Capacity }}{\text { CHarger output current }} \\
& =\frac{35 \mathrm{Ah}}{15 \mathrm{~A}} \\
& =\underline{\underline{2.3 \mathrm{~h}}}
\end{aligned}
$$

\section{RESULTS \& DISCUSSION}

\subsection{Speed Variation with time}

ADV Vehicle moving system consisted of Wiper motors. We used them cause of the high torque and worm and worm wheel system. So then we identified the advantages of using this motor. This means that when we are using this motor, we got some results.

The speed of the motor increase with the time and after 10 Second it comes to higher Speed 38RPM.

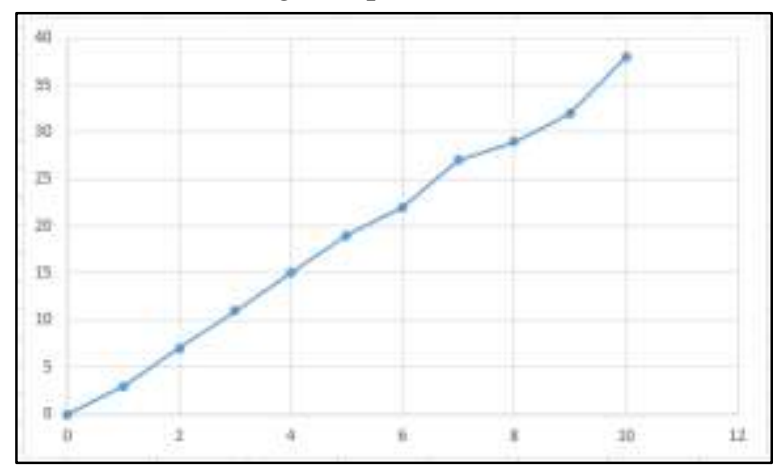

Figure 3 - Speed Variation by time

\subsection{Maximum Load and speed Variation}

ADV consisting of wiper motors. Here, the results tested the maximum load this can be delivered and the speed variation when put loads on the chamber.

The speed without load is $38 \mathrm{rpm}$. But when loads were put into the chamber, the speed decreased. From below graph can identify how it varies.

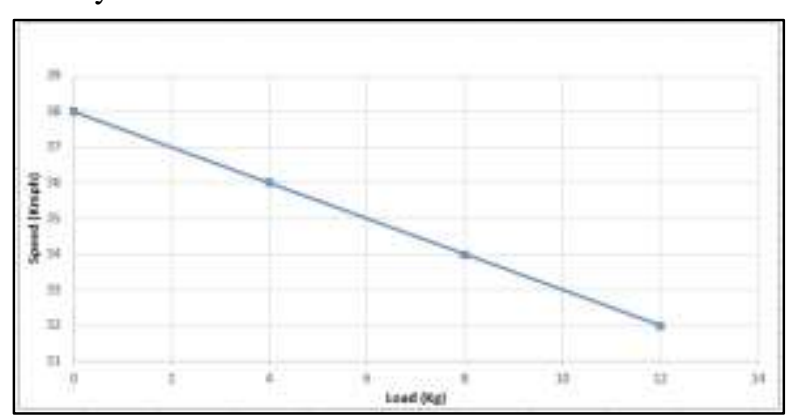

Figure 4 - Speed Variation to Load

\subsection{Electronic Speed Controllers Performance}

The Electronic speed controller that we use for ADV is the QuicRun 880 brushed ESC. With this item, we found some results when using and testing this with ADV. So there, we found ESC Works well with Wiper Motors. This means for wiper motor get $8 \mathrm{~A}$ in no-load and get $15 \mathrm{~A}$ with a load. So the cause of that, other ESCs that we tested Hobbby wings did not give us the best performances.

But this one has given us the performances that we expected. We found ESC worked well there, and it did not heat cause of the heat sink and fan provided by the manufacturer. 


\subsection{Transmitter working Range}

We used the Flysky transmitter \& receiver for communication for Automated Delivery Vehicle, so here we got some results with this transmitter \& receiver. We tested how this transmitter works and then identified that it works only for the $900 \mathrm{~m}-700 \mathrm{~m}$ range. But manufacturers described it as $1000 \mathrm{~m}$. so this is not the perfect brand for this purpose.

Another thing is the range is $1 \mathrm{Km}$ caused us to select this model. Because this is the best one in that range, so we can use other models like Deveolton, RadioLink, etc.

\subsection{FPV Camera System}

The camera system is working with RF signals. So here, we measured and identified the distance that the transmitter and receiver could communicate.

We use the camera in one position and then move the receiver and receiver put in one position and move the camera. From that two types of a system, we identified one thing. This camera works for the $700 \mathrm{~m}-500 \mathrm{~m}$ range, and the camera's signal is very smooth, and the video is the best quality from start point to endpoint.

For this, we used the Go FPV android application that supports this transmitter and receiver. As a result, we could get the range that they provide for specification as $800 \mathrm{~m}$. That comes to true with this experiment, and another unique thing is the signal strength works with high quality in the open area and for cover area signal sometimes loss.

\subsection{Storage Chamber}

The storage chamber we Designed to deliver goods of parcels and boxes. So for this chamber can add more weight because the chamber size is so large. However, here we have a problem with motor power. This means the wiper motors cannot handle the significant weight. We decided to put $12 \mathrm{Kg}$ for the chamber for this prototype vehicle for the safety of the system.

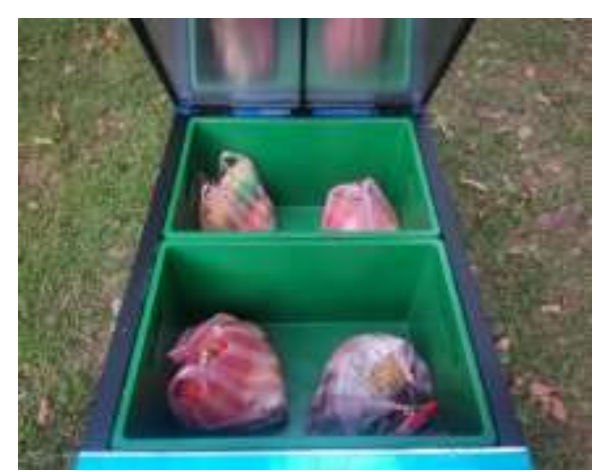

Figure 4 - Goods storing Method 1

From the above picture, you can see how to store the parcels in the storage chamber. Initial plan was to divide the chamber into smaller parts. However, as it may affect the delivery of goods with large size, it has decided to go with above design.

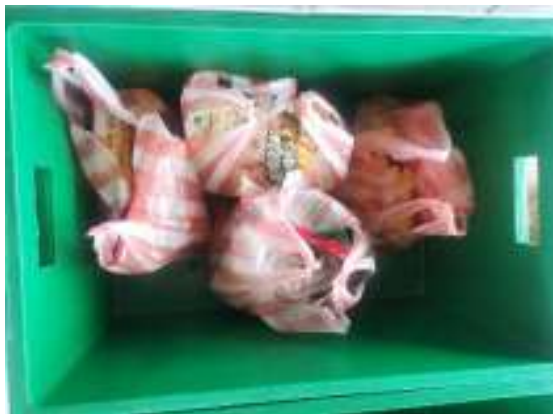

Figure 5 - Goods storing Method 2

Another method of storing goods for delivery in the storage chamber is shown in figure 5 . But the safe and accurate system is shown in figure 4 . Because the bags that are put in the chamber have the same weights. But storing all these things in one chamber means that need more power for the move.

\section{CONCLUSION}

Design \& Implement development of the Automated Delivery Vehicle that will benefit Sri Lanka and the operating system specially designed for Sri Lanka. Here the main objective we imaged as delivering goods for the lockdown areas that people cannot reach with this Covid - 19 virus pandemic. We know this pandemic is not over yet. Therefore, we propose this system as a solution for an excellent delivering system. We saw any people could not reach lockdown areas, a cause of that is the people who live there have to face more problems without food. Another thing is e saw the Lorries that sell goods in the villages, which would be the key point for spreading the virus everywhere. Therefore, we recommended the Automated Delivery vehicle for those works.

Another thing is if we can develop a delivery system islandwide like this the more problems of good delivering will be going out. Another notable thing about this vehicle is this is a fully electric vehicle, and this has zero emission for the environment, which is the important thing. Because of this pandemic, we discuss environmental conditions. Finally, we can recommend this system for Sri Lanka, and we hope this will be the next revolution of goods delivering systems in Sri Lanka.

\section{REFERENCES}

1. B. Van Meldert and L. De Boeck, "Introducing autonomous vehicles in logistics: a review from a broad perspective," p. 42, 2016.

2. K. Bimbraw, "Autonomous cars: Past, present and future: A review of the developments in the last century, the present scenario and the expected future of autonomous vehicle technology," ICINCO 2015 12th Int. Conf. Informatics Control. Autom. Robot. Proc., vol. 1, no. January 2015, pp. 191-198, 2015, doi: 10.5220/0005540501910198. 
3. G. Ullrich, "Automated Guided Vehicle Systems," Autom. Guid. Veh. Syst., 2015, doi: 10.1007/978-3662-44814-4.

4. D. Jennings and M. Figliozzi, "Study of road autonomous delivery robots and their potential effects on freight efficiency and travel," Transp. Res. Rec., vol. 2674, no. 9, pp. 1019-1029, 2020, doi: $10.1177 / 0361198120933633$.

5. M. Raza, "Autonomous Vehicles: Levels, Technologies, Impacts and Concerns," Int. J. Appl. Eng. Res., vol. 13, no. 16, pp. 12710-12714, 2018, [Online]. Available:http://www.ripublication.com.

6. Volpe, "Emerging Automated Urban Freight Delivery Concepts : State of the Practice Scan". National Transportation Systems Center, 2020.
7. S. Hausler, K. Heineke, R. Hensley, T. Möller, D. Schwedhelm, and P. Shen, "The impact of COVID19 on future mobility solutions," McKinsey Cent. Futur. Mobil., no. May, p. 6, 2020, [Online]. Available:

https://www.mckinsey.com/industries/automotiveand-assembly/our-insights/the-impact-of-covid-19on-future-mobilitysolutions?deliveryName=DM62963. 